\title{
"Quiero Recuperar el Control". Un Caso de Terapia Individual desde el Enfoque Sistémico
}

\section{"I Need to be in Control Again". A Case of Individual Systemic Psychotherapy}

\author{
Alicia Moreno Fernández \\ Universidad Pontificia Comillas de Madrid, España
}

\begin{abstract}
Resumen. Este artículo ilustra la aplicación del enfoque sistémico a un caso de psicoterapia individual. Se presentan inicialmente los conceptos y herramientas sistémicos clave para entender cómo se produce el cambio terapéutico. A continuación se expone el caso en el que se muestra la aplicación de estas herramientas: la redefinición relacional y contextual del problema, la identificación y modificación de las pautas de interacción repetitivas, y el abordaje de las narrativas individuales, familiares, sociales y de género que mantienen el síntoma.

Palabras clave: terapia sistémica individual, el cambio desde el modelo sistémico, enfoque de género, modificación de pautas de interacción.
\end{abstract}

\begin{abstract}
This article presents a case of individual systemic psychotherapy. The first part presents the key systemic concepts and therapeutic tools that account for the therapeutic change. Then comes a description of the use of these techniques in this therapeutic process: the relational and contextual redefinition of the problem; the assessment and intervention on the repetitive interactional patterns, and the focus on individual, family, social and gender narratives that maintain the symptom.
\end{abstract}

Keywords: individual systemic psychotherapy, change in the systemic model, gender issues in therapy, changing interactional patterns.

\section{Introducción. La psicoterapia desde el modelo sistémico}

El relato del caso que se presenta a continuación pretende ilustrar algunos de los conceptos y herramientas básicos del paradigma sistémico, mostrando cómo un enfoque tradicionalmente asociado al trabajo con parejas y familias se puede aplicar a una paciente en psicoterapia individual, manteniendo la atención en las relaciones familiares, las interacciones y el contexto.

Lo más significativo del enfoque sistémico y de los diferentes modelos que forman parte de él (estructural, estratégico, intergeneracional, etc.) es la noción de que las conductas de los individuos (incluidas las problemáticas o disfuncionales), adquieren un significado o cumplen una función en su sistema relacional significativo, que suele ser su familia actual o su familia de origen (Papp, 1994). Los sistemas relacionales mantienen un

La correspondencia sobre este artículo puede dirigirse a la autora al E-mail: amoreno@iuf.upcomillas.es 
equilibrio u homeostasis, al establecerse determinados roles y patrones estables de interacción entre sus miembros. En determinados momentos del ciclo vital o debido a cambios no previsibles en el entorno o en alguno de los individuos, esta homeostasis se rompe, y el sistema debe encontrar un nuevo equilibrio, incorporando nuevas formas de relación entre los individuos que forman parte de él (Carter y Mc Goldrick, 2005).

Tanto si se trabaja con una pareja o familia como si se trata de una terapia individual, el foco del modelo sistémico está en las interacciones y el contexto. Esto implica pasar de lo puramente intrapsíquico a lo interaccional, preguntándonos cuáles son los circuitos de interacción que mantienen el problema. Estas interacciones son, con frecuencia, intentos de solución ineficaces ("la solución que se convierte en el problema”, en palabras de Waztlawick), y se dan entre la persona sintomática y su entorno, o en las propias estrategias que pone en marcha el paciente para intentar manejar sus dificultades (Watzlawick, Weakland y Fisch, 1976). La identificación y posterior bloqueo y modificación de estos circuitos de interacción que sostienen el problema es una de las herramientas básicas del modelo sistémico (Haley, 2009).

El cambio terapéutico se produce también al favorecer una nueva percepción o significado relacional o contextual del problema, utilizando herramientas terapéuticas como el genograma (esquema de las relaciones familiares en tres generaciones) y preguntas que exploran ese contexto relacional: “¿Para quién más es un problema? ¿Cómo perciben esta situación otras personas significativas? ¿En qué momento surgió el problema? ¿Qué ha cambiado en las relaciones antes y después de su aparición? ¿Quiénes o qué creencias sostienen el problema o el no cambio? ¿En qué circunstancias, con quién, cuándo disminuye o desaparece el problema?”. El contexto que exploramos va más allá de la historia de la familia de origen, y contempla también los valores culturales, sociales, religiosos, de género, de clase social, etc., a partir de los que la persona y la familia han interpretado y dado sentido a la realidad. El terapeuta actúa no tanto como un "técnico" que ayuda a reparar o sustituir circuitos de interacción atascados, sino como un co-creador de nuevos significados junto con el paciente, revisando el origen de las narrativas o guiones familiares o culturales que han prevalecido en su vida hasta ese momento y dialogando con él para construir entre ambos nuevas posibilidades (Sluzki, 1992; White, 1997).

El caso que se describe en este artículo es una terapia individual iniciada hace 10 meses, aún en curso, en la que se ilustran tres ejes del trabajo terapéutico: (a) la redefinición relacional y contextual del problema, (b) la intervención sobre los circuitos de interacción repetitivos y (c) la revisión de la narrativa a través de la que se construye y mantiene la visión de la realidad de la paciente. Mi modelo de terapia se basa en conceptos teóricos y estrategias terapéuticas del enfoque intergeneracional (McGoldrick y Gerson, 2006; Mc Goldrick, Anderson y Walsh, 1991), el modelo del Mental Research Institute (Watzlawick, Weackland y Fisch, 1976), la terapia estratégica y breve (Beyebach, 2006; Haley, 2009; Papp, 1994), la terapia narrativa (Sluzki, 1992 y White, 1997), el enfoque colaborativo (Andersen, 1994; Friedman, 1995) y la perspectiva de género (Lerner, 1990; Walters y otras, 1996).

Se parte de una concepción de la relación terapéutica en la que terapeuta y paciente asumen co-responsabilidad por el cambio. Se trata de construir con la paciente una nueva visión de sí misma más comprensiva y positiva, que subraye sus capacidades y sus movimientos hacia el cambio. Se revisa su "narrativa" de forma que la paciente comprenda cómo sus relaciones más significativas han influido en su posterior forma de percibir y actuar en el mundo, y a la vez, reconozca la influencia que ella tiene ahora sobre esos patrones de relación que ya no son tan funcionales. En el contexto de esta relación de colaboración, el trabajo terapéutico se enfoca en los cambios concretos que la paciente va realizando, buscando siempre datos mensurables para paciente y terapeuta. “¿Qué fue diferente de la semana pasada? ¿Qué logró decir o hacer ahora, y que no sucedía antes de acudir a consulta? ¿En qué acciones concretas de su vida cotidiana se pueden traducir los nuevos aprendizajes que realiza la paciente en terapia?" Evidentemente, en las nuevas estrategias de cambio puestas en marcha tanto por la terapeuta como por la paciente tenemos siempre en cuenta qué es lo que ya se intentó anteriormente y no funcionó, para no volver a repetir esos intentos de solución fallidos y avanzamos en terapia utilizando como guía el feedback de la paciente ante las intervenciones terapéuticas. En ese sentido, la redacción de este artículo ha servido también como estímulo a la terapia y un nuevo paso de la paciente en dirección al cambio, mostrando 
aquellos aspectos de sí misma que hasta hace poco luchaba por mantener ocultos, y confiando en que su experiencia pueda ser útil para otros pacientes y terapeutas.

\section{Evaluación inicial del caso}

Motivo de consulta: Sara (nombre ficticio) es una mujer soltera de 34 años, emigrante de un país latinoamericano, que acude a consulta porque "quiere dejar de sentirse tan mal". Está tomando medicación antidepresiva desde hace varios meses pero su estado anímico no ha mejorado significativamente, así que ha decidido finalmente pedir ayuda psicoterapéutica. El desencadenante inicial de la consulta fue la ruptura de una relación sentimental que duró varios meses, y en la que puso mucha ilusión y esperanzas. Fue ella quien tomó la decisión de no continuar esta relación, ya que sentía que él quería simplemente "pasar el rato" y no asumir ningún compromiso.

Otros datos significativos sobre su situación actual: Sara tiene un trabajo de un alto nivel de responsabilidad y exigencia en una empresa muy prestigiosa. Ha ido ascendiendo profesionalmente a costa de una gran dedicación y de tolerar el estrés y la tensión de este entorno de trabajo muy competitivo. Estudió Economía en su país de origen, compatibilizando los estudios con el trabajo, y consiguió una beca para venir a España a estudiar un Máster. Regresó y trabajó en su país durante dos años y posteriormente decidió volver a Madrid, donde reside desde hace cuatro años. Toda su familia extensa vive en su país de origen. Al iniciar la terapia vivía en un piso compartido con una compañera de su país, amiga de su familia. Sara dedica mucho tiempo a su trabajo y apenas tiene contacto con los pocos amigos o amigas que ha conocido en Madrid. Reconoce que le cuesta mucho abrirse y relacionarse más, aunque se siente sola. Anteriormente tenía más contacto con la comunidad de la iglesia protestante a la que pertenece, aunque últimamente también se ha distanciado de este entorno. Esta paciente estuvo anteriormente en terapia, en su país de origen, justo antes de venir a España, y siente que le ayudó mucho en esa etapa en su decisión de salir de su país y venir aquí. Es una mujer inteligente, muy guapa y con un aspecto físico muy bien cuidado, con un aire triste aunque muy contenido y con una actitud un tanto reservada.

Hasta ahora Sara no había tenido ninguna relación de pareja, excepto una relación platónica con un compañero de trabajo en su país de origen. Reconoce que se ha mantenido muy cerrada a las relaciones con hombres, utilizando el trabajo y las creencias religiosas como "protección". En esta relación sentimental reciente, Sara dio el paso de acercarse física y emocionalmente a un hombre, superando sus recelos iniciales al ver que él no era tan creyente como ella. Sintió por primera vez "la ilusión de sentirse acompañada", y el deseo de que la relación se afianzase, pero comprobó gradualmente la falta de implicación de él: "no sabía si iba en serio o seguía saliendo con otras chicas". Finalmente ella decidió cortar la relación, después de varios intentos y posteriores reconciliaciones.

Esta experiencia ha tenido un impacto emocional muy grande en Sara, ya que se le hace "mucho más difícil sobrellevar la sensación de soledad" y se siente "hundida, ha perdido el control sobre sus sentimientos". Conecta el dolor que sufre ahora con el que sentía cuando se despedía de su madre después de sus visitas (hija de padres separados, la paciente dejó de convivir con su madre a los 11 años para ir a vivir con su padre y la familia de éste). A pesar de que durante mucho tiempo tuvo una sensación de soledad, de falta de pertenencia y desprotección, ha salido adelante dando una imagen de aparente estabilidad, ocultando o negando su dolor y "centrándose en hacer lo que tenía que hacer y cumplir con su deber". Ahora esta estrategia ya no le funciona, por mucho que intenta "volver a sentirse como antes y que las cosas no le afecten tanto". De ahí viene su petición de ayuda inicial: "quiero recuperar el control sobre mis sentimientos".

Apenas ha hablado con nadie de lo que le está pasando ahora, excepto con una amiga de su país y su madrastra, con quien tiene buena relación. No confía en que si se lo cuenta a su madre ésta sea capaz de consolarla, y teme que probablemente se angustiaría más. Además, reconoce que ahora le cuesta aún más acercarse a la gente y se ha vuelto más desconfiada, por miedo a que le vuelvan a hacer daño. 
Estos son los datos recogidos en las primeras entrevistas, en las que exploramos el motivo de consulta, los datos básicos de la situación actual de la paciente, incluido su contexto relacional, las circunstancias que la llevan a consultar ahora, el grado de motivación inicial para el cambio, y la descripción del problema y de la posible solución que da la paciente. Llama la atención que ella viene a consulta con una petición que equivale a "cambiar sin que nada cambie", es decir, eliminar el sufrimiento actual sin cambiar nada más de su vida, volver al "equilibrio" u homeostasis anterior "en la que no sentía dolor, y tenía el control". Dado que su primer intento de solución (la medicación antidepresiva) no ha funcionado, hace otro intento a través de la terapia. Aunque evidentemente uno de los objetivos terapéuticos es ayudarle a manejar y aliviar ese dolor, iremos construyendo con Sara a lo largo de éstas y las siguientes sesiones la idea de que esa vuelta atrás (dejar de sufrir al reducir al mínimo su mundo emocional) ya no es posible. Transformamos entonces la demanda inicial de la paciente de "recuperar el control y no sufrir" en "encontrar otra forma diferente de aliviar el sufrimiento y sentirse en control de su vida, sin tener que apartarse de sus emociones". Desde el modelo sistémico habitualmente no contradecimos o confrontamos la demanda inicial del paciente, sino que ésta se redefine o se amplía para abrir la puerta a nuevas posibilidades de cambio.

\section{La familia de origen}

Una de las primeras herramientas terapéuticas que se utilizan en una terapia sistémica es la construcción del genograma, que nos permite dar una perspectiva relacional a las dificultades de la paciente y situar sus problemas actuales en el contexto de su sistema familiar. Para ello, le planteamos "hacer juntas un dibujo, un gráfico de tu familia en tres generaciones, para visualizar mejor de dónde vienes". Dibujamos a las mujeres con un círculo y los hombres con un cuadrado (ver dibujo), y vamos incluyendo a los miembros de su familia extensa, indicando edades, quién convive con quién, quién se independizó y quién no, quién mantiene económicamente a quién, muertes, enfermedades, fechas de acontecimientos significativos y posibles coincidencias entre sucesos... Vamos a tener así, en poco tiempo un diseño del contexto relacional, cultural, de redes, donde acontece el problema que antes aparecía como individual. Al ir explorando el genograma también iremos explorando la clase de vínculos que conecta a los distintos miembros (sobreinvolucrados, afectuosos, conflictivos, distantes, etc.)

\section{Genograma}

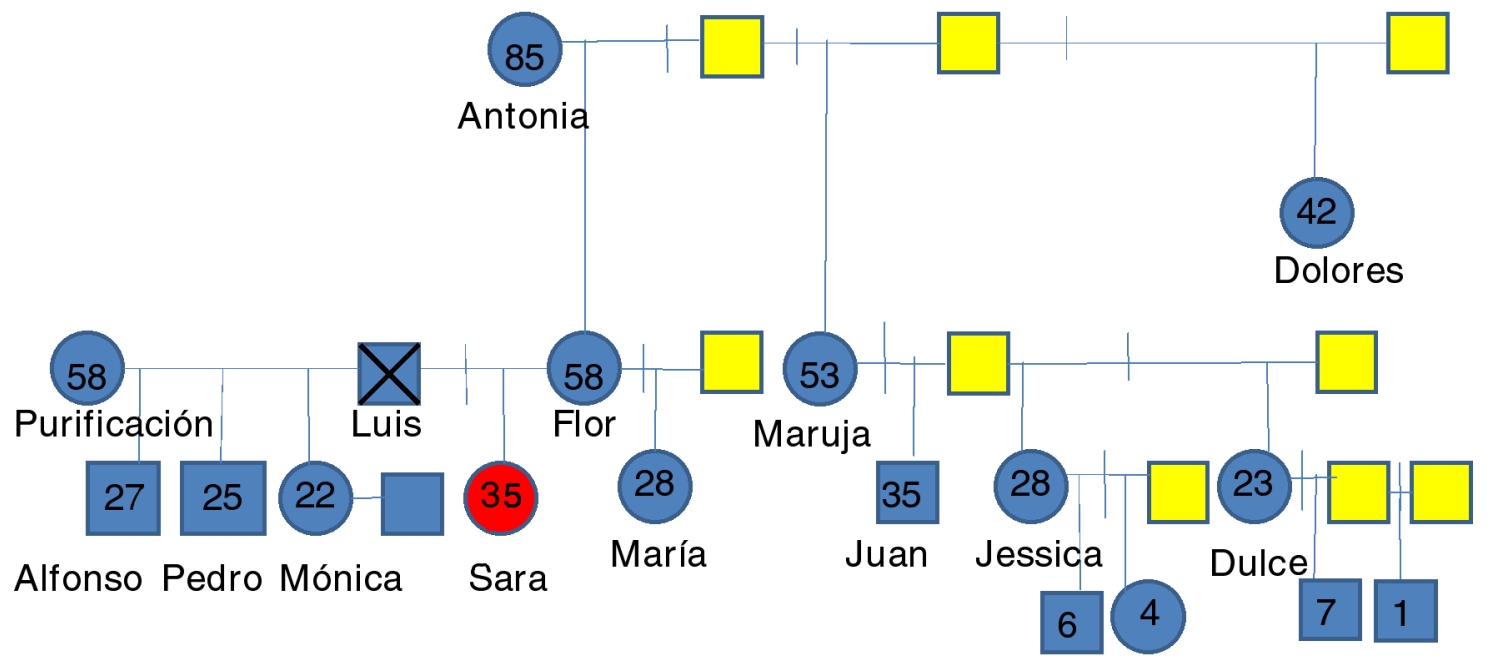

En amarillo aparecen los hombres que han permanecido ausentes de las relaciones familiares 
Composición de la familia de origen: Los padres de Sara vivieron juntos únicamente unos meses. Sara convivió hasta los 11 años con su madre y la familia de ésta (abuela, tías y primos) y posteriormente con su padre y la familia de éste (esposa y tres hijos menores que Sara).

Familia materna: La abuela materna de Sara es Antonia, de 85 años, que fue madre soltera y tuvo tres hijas, Flor, Maruja y Dolores. La hija mayor es Flor, de 58 años, que tiene dos hijas: Sara, fruto de su relación con Luis, y María (28 años), hija de otro hombre con el que no convivió. La segunda hija de Antonia es Maruja, de 53 años, tía de Sara, que también ha sido madre soltera y tiene tres hijos fruto de relaciones con dos hombres: Juan, un varón de 35, y dos hijas fruto de una segunda pareja con quien convivió dos años: Jessica de 28 y Dulce de 23. Jessica tiene una enfermedad crónica que limita su esperanza de vida, aunque de momento conserva un buen estado de salud. Es madre soltera de dos hijos, un niño de 6 y una niña de 4 . El padre de los niños mantiene una cierta implicación en la crianza. La hija menor, Dulce, de 23, tuvo un hijo de 7 años con un hombre con quien convivió un tiempo, y acaba de tener un hijo fruto de otra relación esporádica. Dulce reside ahora mismo en otro país cercano donde trabaja, y es su madre, Maruja, quien se hace cargo del niño de 7 años. Finalmente, la tía menor de Sara es Dolores, de 42 años, que sufre un retraso mental severo y convive en el mismo domicilio que la abuela, madre, hermana, tía y primos de Sara. La madre de Sara trabajó como empleada doméstica, y pasaba temporadas residiendo fuera y visitando su propio domicilio familiar los fines de semana. En la actualidad tiene varias enfermedades físicas que limitan su movilidad y capacidad de realizar trabajo físico, así que gana algo de dinero esporádicamente trabajando desde su casa como cocinera y depende económicamente de Sara. El resto de la familia materna (la abuela, las dos tías y las primas) también dependen parcialmente del apoyo económico de Sara, puesto que estas mujeres tienen trabajos inestables y mal remunerados, y los padres de los hijos de Jessica y Dulce no se hacen cargo económicamente del mantenimiento de estos.

Familia paterna: Sara fue trasladada del domicilio materno al paterno a los 11 años, para criarse con su padre en un entorno socioeconómico más favorable (el padre tenía su propio negocio con el que mantenía económicamente a la familia) y asistir a un mejor colegio. Hasta entonces el contacto con el padre había sido esporádico, en las contadas ocasiones en que éste acudía al domicilio materno para llevar el dinero de la manutención, o en las visitas ocasionales de Sara al domicilio del padre. En este núcleo familiar Sara convivió con el padre y la esposa de éste, Purificación, que trabajaba como secretaria, y con los tres hijos de ellos dos: Alfonso, que ahora tiene 27 años, Pedro, de 25, y Mónica, de 22, que hasta su boda reciente convivía con su madre y dos hermanos mayores. Los tres tienen estudios universitarios. Purificación ha sido siempre una mujer muy devota de la iglesia protestante, a la que acudieron también todos los miembros de la familia, incluida la propia Sara. El padre, Luis, murió hace tres años.

Relaciones en la familia de origen: La principal figura de apego en la infancia de Sara fue su madre. No desarrolló un vínculo especialmente cercano con sus tías maternas ni con la abuela, a quien percibía como "una mujer dominante y de carácter difícil". Sara echaba de menos contar con la presencia más continua de su madre, que tenía que ausentarse con frecuencia del domicilio, por su horario y condiciones de trabajo. Lo mismo le ocurrió a la madre con su propia madre, la abuela materna de Sara, que trabajaba algunas temporadas en otra ciudad. Sara siente que ni ella ni su propia madre han tenido a alguien "que haya estado incondicionalmente para ellas".

El cambio que supuso abandonar la casa materna a los 11 años para ir a vivir con el padre es descrito por Sara como muy duro y traumático. Ocurrió sin previo aviso, con la justificación de que así podría acudir a un buen colegio privado cercano al domicilio del padre, que vivía en otra parte de la ciudad. Ella apenas tenía relación con él, que era para ella "un extraño", una especie de familiar lejano al que veía de visita ocasionalmente. Sara dice que durante muchos años sintió que aquella "no era su casa". Nunca llegó a sentir una cercanía afectiva con su padre, aunque reconoce que le afectó mucho la muerte de él hace tres años en un accidente de tráfico, cuando ella ya vivía en España. Le sorprendió la sensación de pérdida tan grande que tuvo. "Él estaba orgulloso de mí y de todos los logros que yo había conseguido; en cierto modo me hacía sentir especial; fue quien más me animó a estudiar y venir a España. Al morir él, perdí un apoyo, ya que era el único que no espe- 
raba que yo me ocupase de él'". A partir de entonces, la madrastra se apoyó un poco más en ella, queriendo contar con su ayuda en la relación con sus hijos, y con algo de apoyo económico.

Poco después de que Sara se trasladase a vivir con el padre, dejó de ver a su madre durante los dos años en los que trabajó fuera del país. En esa época Sara volvía de visita al domicilio de la familia materna con la abuela y las tías, y al menos allí sentía más "calor" y sensación de bienvenida, en comparación con la distancia y una cierta frialdad que sentía en la casa paterna. Aunque se sintió bien tratada por el padre y la madrastra, quienes "no hicieron diferencias entre ella y los tres hermanos menores", reconoce que en ese ambiente familiar "no se mostraban mucho los sentimientos y todo se trataba como con guantes de seda", con delicadeza y buenas formas. Ella se sentía profundamente triste y recuerda como momentos especialmente dolorosos aquellos en que volvía a casa del padre y tenía que despedirse de su madre después de pasar unos días con ella. Era un dolor muy profundo ante la pérdida y el abandono que se vuelve a evocar ahora cuando sufre una ruptura sentimental. Sara echaba de menos que su padre o su madrastra se acercasen a ella para cuidarla o consolarla cuando se sentía tan mal, aunque ella intentaba no expresar sus emociones ni quejarse o reclamar explícitamente más cercanía. Simplemente, se quedaba callada y se aislaba. Sara era obediente y ayudaba a su madrastra con las tareas de la casa y el cuidado de los hermanos pequeños. Fuera de la casa, se centró en estudiar y ser una alumna brillante, y nunca compartió lo mal que se había sentido en esos años. Con el tiempo fue desarrollando una relación más cercana con su madrastra, a la que describe como una mujer "miedosa y precavida, temerosa del mundo externo a la familia". Reconoce que quizá a ella "se le contagió" un poco de este control y desconfianza. El padre, que vivió dedicado a su familia, fue en cambio un "soñador", siempre planificando y comenzando otros nuevos negocios (además del que mantuvo de manera estable toda su vida) que acababan siendo ruinosos.

Con estos elementos de la historia clínica podemos plantearnos la hipótesis de que la paciente ha vivido varias situaciones relacionales traumáticas en su familia de origen, debido a las ausencias de su madre por motivos de trabajo, la separación de ella al irse a vivir con el padre, la pérdida de su hogar original, y la dificil adaptación a la nueva familia del padre. A partir de estas experiencias desarrolló un patrón de conducta evitativa, desdeñosa, disociada, retraída, poco afectiva. Este tipo de respuesta le permitió en un primer momento manejar el impacto de la separación traumática de su madre, la falta de apego con el padre y la sensación de desprotección y falta de pertenencia. En la actualidad sigue repitiendo esa conducta de retracción, distancia, esfuerzo puesto en el trabajo para ser querida y aceptada, de forma que así logra "controlar" las emociones. Al producirse la pérdida del vínculo con el primer hombre con quien tiene una relación afectiva, conecta ese dolor con el que sentía por la separación de la madre, y responde de la misma manera, con control y retracción.

Con estos datos, nos planteamos en terapia redefinir esa pauta de conducta (una armadura emocional que en su momento la protegió pero que ahora la inmoviliza), y encontrar herramientas para que Sara pueda manejar sus afectos y las relaciones de un modo diferente. Siguiendo la premisa de "hablar el lenguaje del cliente" (Waztlawick, 1989) utilizamos nociones de control-dolor semejantes a la definición de la paciente pero ligeramente modificadas. Quizás no podamos aliviar el dolor pero sí entender cómo este proceso actual se parece al viejo y así destejer el nexo control-bienestar y descontrol-angustia. Nos proponemos buscar un camino para que se pueda acercar a la gente con una protección distinta que la distancia, transformando su "armadura" en un "escudo móvil". Ésta es una imagen visual poderosa que alude a sus creencias: persona religiosa, metódica que puede mantener un control pero al mismo tiempo explorar diferentes modos de vincularse.

\section{Otra experiencia traumática}

Al inicio de la terapia Sara mantenía una actitud algo reservada y distante, tal como suele hacer en el resto de relaciones. Era muy importante, por tanto, construir una relación terapéutica que generase en ella una 
sensación de confianza en mí, en mi intención de conocerla y ayudarla, y facilitar así una mayor apertura y acercamiento. Al cabo de un tiempo, cuando empecé a tener la sensación de que quizá había algunos temas de los que no hablábamos en terapia, se lo comenté y ella reconoció que sí, que había algo, pero que no quería hablar de ello porque "removerlo no iba a servir para nada". Admitió, cuando le pregunté, que se trataba de una experiencia de abuso. Le dije que es muy común que quienes han sufrido una experiencia así sean reacios a volver a hablar de ello, por el dolor, la vergüenza o incluso la culpa que les crea, pero que precisamente esa era la razón por la que sería tan importante hablarlo en algún momento, cuando ella lo decidiese. Las experiencias traumáticas que se dejan encerradas son como una casa que se mantiene cerrada; a veces hace falta abrir puertas y ventanas para que se escapen los fantasmas y entre de nuevo el aire y la luz. Además, sería importante hablar de ello no sólo por lo que ocurrió entonces, sino porque ese tipo de experiencia seguramente seguía ejerciendo una influencia ahora mismo sobre su vida, sus relaciones, sus miedos... No volví a insistir, aunque unos meses después, con la relación terapéutica más consolidada, le volví a preguntar sobre este tema, al hablar de sus dificultades para confiar en los demás, y entonces me contó su experiencia.

El abuso ocurrió cuando ella tenía de 5 a 7 años y vivía con su madre. Sara pasaba mucho tiempo en la calle con otros niños y niñas, e iba con frecuencia a la casa de una familia vecina, en la que una de las hermanas mayores se sentaba con ella a jugar o a hacer los deberes. Los dos hermanos menores en la familia, adolescentes, fueron quienes abusaron de ella. La llevaban a un cuarto a "jugar", y ahí ocurrían los tocamientos. Ella nunca habló de esto, y parece que nadie se dio cuenta de lo que estaba ocurriendo. Al recordar estos episodios, a Sara le llama la atención darse cuenta de lo desprotegida que estaba; nadie se ocupaba en vigilar dónde o con quién estaba: "no recuerdo que nadie me cuidase en mi casa". Cuando más adelante se fue a vivir a la casa paterna se dio cuenta de que la madrastra, Purificación, era muy sobreprotectora de su hija menor y que se preocupaba por que la niña nunca estuviese sola en compañía de desconocidos, especialmente varones. Esa mirada de protección de su madrastra hacia su hermana menor era algo que ella nunca había recibido. Sara no le contó a nadie en su familia lo que había ocurrido ni habló de ello hasta hace unos años, con una íntima amiga.

A partir de esta experiencia traumática podemos entender aún más cuál ha sido el tipo de respuesta de Sara ante otros traumas y situaciones vitales críticas que le tocó vivir posteriormente: la separación de la madre, el traslado al ambiente más frío y formal de la casa paterna, el posterior exilio y la separación de la comunidad religiosa en la que se relacionaba, la muerte del padre, la ruptura amorosa y el trabajo actual hiperexigente. En todas estas ocasiones su afrontamiento ha sido semejante: aparentar que no pasaba nada, esforzarse, exigirse más, ocultar sus emociones, no sentir. Esta desconexión interna o disociación es muy típica de las vivencias traumáticas y es ampliada por el concepto de "sistemas organizados alrededor del trauma" (Bentovim, 2000), que describe los patrones de relación que se establecen y perpetúan a partir del trauma original. En el caso de Sara, este modo de respuesta organizó en cada oportunidad los tipos de vínculos, hizo que los demás esperaran mucho de ella y que ella pidiera muy poco. La frustración creció en ella, y eso la hizo a su vez sumamente vulnerable. Sara vive en un mundo sin matices, de todo o nada. Espera una relación idealizada con un hombre, alguien que finalmente la va a cuidar y proteger. Pero a la vez mantiene un estilo de relación en el que al menor fallo se enfada y se retira para siempre; su única forma de protegerse es cortar el vínculo, y esto contribuye a que cada vez se sienta más sola. Al volverse sumamente vigilante y exigente con los hombres, añade presión a la relación, y contribuye paradójicamente a que el otro se aleje.

\section{Pautas de relación repetidas}

Una vez que hemos identificado las experiencias relacionales clave y algunas de sus implicaciones, abordamos en terapia cómo la paciente sigue repitiendo determinados roles (de proveedora y trabajadora eficaz, dispuesta a cumplir las expectativas de su familia o el trabajo), y patrones de relación (distancia, control) en dis- 
tintas relaciones o contextos (familia de origen, trabajo, pareja, relaciones con amistades). Intervenimos sobre estos patrones disfuncionales que se repiten, señalando también su utilidad o funcionalidad hasta ahora; paralelamente, nos centramos en identificar, reforzar y ampliar todo lo que es un poco diferente, los pasos hacia el cambio, las nuevas narrativas. Nos enfocamos en lo que la paciente sí es capaz de hacer, más que en sus carencias, y construimos con ella una visión más positiva de sí misma.

Relación actual con su familia de origen: Sara es, en cierto modo, la proveedora emocional y económica de su familia materna. "Mi madre se apoya en mí, es como si yo fuese la madre de mi madre. No le puedo decir que tengo problemas o estoy mal, porque entonces ella se angustia y se preocupa". La madre la ve con admiración, "me dice que soy lo máximo", aunque por otro lado ella no se siente realmente tenida en cuenta en sus sentimientos o necesidades (que casi nunca manifiesta). Su hermana materna, María, siente celos de ella y a su vez, también reclama a Sara más atención y disponibilidad. La madre tiene varios problemas de salud, pero no se cuida ni deja de hacer trabajos físicos que no le convienen. Acaba empleando parte del dinero que Sara le envía mensualmente para su manutención en otras necesidades de la abuela, tías o primos, o en gastos generales del domicilio. Es frecuente que acabe pidiendo más dinero a su hija a mediados de mes. Sara también aporta un dinero mensual a su madrastra, "que desde que murió el padre, parece que quiere que yo le sustituya un poco". En este caso no siente tanto la presión económica, pero sí la demanda emocional de Purificación, que le pide ayuda para "hacer entrar en razón" a uno de sus hijos varones.

El trabajo: Sara ha funcionado hasta ahora muy bien en su entorno laboral extremadamente exigente y competitivo, y ha ido consiguiendo ascensos y mejoras económicas. En cierto modo, volcarse en el trabajo le sirve para desconectar de sus sentimientos; cumplir eficazmente con sus tareas le da esa sensación de control que ella busca. Puede manejar bastante bien las relaciones con jefes y clientes, siempre desde una cierta distancia, y no llega casi nunca a intimar demasiado con sus compañeros. Nadie sabe prácticamente nada de su vida personal. El grado de exigencia en el trabajo es tal que apenas le queda tiempo libre para sí misma, ni siquiera a veces en los fines de semana. Sara empieza a plantearse cómo poner algún límite a su dedicación y guardar un cierto espacio para su vida privada, aunque cuando no está trabajando se da cuenta de lo sola que está y se deprime.

Tanto en la familia como en el trabajo Sara se centra en "hacer lo que hay que hacer": cumplir con sus obligaciones, ser eficaz y estar a la altura de las expectativas del otro, por muy exigentes que sean. Esto le devuelve en ambos contextos una imagen positiva y valorada de sí misma, aunque las demandas son continuas y crecientes (siempre hay más necesidades y gastos que cubrir en su familia, o más logros que conseguir en el trabajo), imposibles de satisfacer por mucho que ella se esfuerce. El tipo de empresa multinacional y muy competitiva donde trabaja Sara se nutre y a su vez realimenta el modo de funcionamiento de personas como ella: orientadas al logro, necesitadas del reconocimiento externo de su éxito, y desconectadas de sus necesidades emocionales. Su éxito laboral es a la vez una "solución" (le aporta una sensación de valía y una visión de sí misma como persona responsable y eficaz) y un "problema" (acaba siendo una especie de robot, una máquina de trabajar deshumanizada que se mantiene desconectada de sus sentimientos).

La labor terapéutica se centra en ayudar a Sara a ver cómo se queda atrapada en esta exigencia y autoexigencia de ser la mejor y más capaz, y cuáles pueden ser para ella las alternativas para vivir atendiendo también sus propias necesidades, y no sólo las demandas externas. ¿Están el éxito profesional o el deber hacia su familia por encima de cualquier otro valor o necesidad en su vida? Ante las expectativas siempre crecientes de su familia o del trabajo, ¿tiene ella algún límite?, ¿cuánto y hasta cuándo está dispuesta a seguir dando?, ¿puede empezar a conectar con sus propios deseos y necesidades, en lugar de actuar siempre para satisfacer los del otro?, ¿puede reconocerse como alguien que, además de tener recursos y capacidad para cumplir objetivos, tiene necesidad de afecto, de descanso, de cultivar sus aficiones?, ¿y cómo satisface ella misma esas necesidades? Evidentemente, empezar a hacer cambios en estos dos sistemas relacionales implica riesgos que ella debe afrontar, reacciones homeostáticas internas o externas que le advierten de los peligros del cambio: ¿qué consecuencias tiene en su entorno laboral poner algún límite?, ¿está dispuesta a buscar nuevas formas 
de aliviar su soledad, en lugar de ocultarla mediante la sobrecarga de trabajo?, ¿qué ocurre si gasta más de su propio dinero en sí misma en lugar de enviárselo a su familia?, es más: ¿tiene derecho a hacerlo?, ¿cómo puede manejar los posibles reproches o la culpa por decir no a su familia? El trabajo terapéutico ha ido ayudando a que Sara tome conciencia de cómo actúa, para qué le sirve, y cómo sus entornos familiar y laboral refuerzan ese rol de proveedora competente. Se trata de ir conectando más con sus deseos (por ejemplo, pararse de vez en cuando durante el día a preguntarse cómo se siente; hacer alguna pequeña actividad placentera cotidiana) y no dejarse aplastar por los mandatos y las exigencias.

Amistades: Sara mantiene una actitud distante y algo desconfiada; suele mostrarse seria, formal y racional, poco comunicativa respecto a su vida personal. Reconoce que "observa mucho a la gente antes de acercarse", está muy pendiente de si la otra persona "es de fiar". Si alguien hace algo que le defrauda, "borra a esa persona de la lista" y se distancia o corta la relación. En su país de origen se relacionaba con gente que conocía a través de la iglesia, donde buscaba personas "coherentes con sus mismos principios religiosos: ser alguien fiable y de palabra, respetuoso y considerado; no hacer nada que pueda dañar o incomodar al otro". Buscó un entorno similar en Madrid, donde participó durante un tiempo en las actividades de una iglesia a la que acudían personas de su país. Aunque entabló algunas amistades, fue luego cortando poco a poco el contacto. Aquella "burbuja" en la que ella creía anteriormente, compuesta por "gente que nunca le iba a defraudar", empezó a venirse abajo al tener algún desencuentro o sentirse decepcionada ante determinados comportamientos de los miembros de esta comunidad que ella consideró poco ejemplares. Estos vínculos se han ido debilitando y Sara apenas los ha sustituido por otros, puesto que tampoco se ha mostrado abierta en el trabajo para entablar amistades, ni ha participado en otras actividades o círculos que le hayan permitido salir de su aislamiento y construir una red de apoyo. Además, la ruptura sentimental y el estado depresivo que sufrió a continuación acentuaron aún más su desconfianza y miedos ante las relaciones.

La terapia ha abordado este tema, ayudando a Sara a validar y hacerse cargo de su necesidad de conexión. Hemos explorado juntas cuáles son las opciones que tiene para recuperar y ampliar su vida social, y he valorado mucho cualquier paso que ella ha dado para estar más conectada, proponiendo tareas concretas como llamar a amigas, realizar alguna actividad de ocio con gente, o invitar a alguien a su casa. A pesar de que inicialmente le cuesta mucho dar estos pasos y encuentra todo tipo de excusas que lo justifiquen, reconoce que una vez que lo hace se acaba sintiendo mucho mejor. Además, es fundamental ver también cómo ella misma construye las barreras que dificultan las relaciones y contribuyen a su soledad. Su alto nivel de exigencia, reflejado en esa ideología de "todo o nada", le dificulta aceptar y reconocer que no existe un mundo ideal (ni siquiera en el entorno de la iglesia) y que todas las personas tienen sus fallos. Aceptar esto en los demás implica también aceptarse a sí misma como una persona imperfecta, en lugar de estar constantemente comparando a los demás y a sí misma con el ideal de perfección al que aspira... y que conduce inevitablemente a la frustración. Otro componente de su patrón de relación habitual que se ha ido modificando es su tendencia automática a desconectarse y alejarse en cuanto se siente decepcionada o frustrada. En lugar de eso, ella puede probar otras alternativas, como volver a acercarse y manejar la relación de forma diferente, mostrando cómo se siente o pidiendo al otro lo que necesita. Sara ha empezado poco a poco a hacer esto, retomando el contacto con algunas amigas y cuestionándose esa creencia en un "mundo perfecto" libre de ambigüedades y de incertidumbres.

Relación de pareja: Aunque Sara ha tenido siempre el deseo de encontrar pareja y formar una familia, los traumas y dificultades que hemos expuesto hasta ahora han contribuido a que apenas haya tenido relaciones con los hombres. Su padre aparece como el único varón en su familia extensa que mantuvo una relación de pareja estable (con la madrastra de Sara), aunque nunca llegó a formar un vínculo cercano con su hija. El resto de hombres en su familia materna no han sido buenos referentes como maridos o padres, ya que han estado prácticamente ausentes del hogar y la crianza de los hijos, y apenas intervinieron durante algún breve periodo en las vidas de su abuela, su madre, sus tías o sus primas, una vez que nacieron sus respectivos hijos. La vivencia infantil de Sara de un cierto abandono emocional y falta de protección contribuyó y a la vez se vio 
incrementada por la experiencia del abuso sexual. En este primer y desafortunado contacto físico y emocional con hombres, estos abusaron de su poder sobre ella, utilizándola para su propia satisfacción y aprovechándose para ello de su vulnerabilidad y dependencia infantil. Su búsqueda de pareja se basa en una imagen idealizada de alguien que es totalmente confiable y que finalmente la va a proteger y se va a hacer cargo de ella; es en cierto modo la búsqueda de una relación que resuelva y compense todos sus traumas pasados. Sin embargo, desde su temor a ser herida, utilizada o abandonada, se vuelve más susceptible a cualquier fallo en el otro, y desde ahí es más probable que el otro se agobie o se aleje.

La relación de pareja cuya ruptura provocó el inicio de la terapia fue vivida por Sara como "la primera vez en que decidí dar el paso de abrirme. Me di cuenta de que me volvía muy dependiente, que sólo quería estar con él. Y luego me he sentido totalmente decepcionada. Además, yo no sabía que era tan sensible, que podía sentir tanto dolor". El abordaje en terapia de los anteriores abandonos y traumas que había sufrido (separación de la madre, abuso sexual, muerte inesperada del padre) sirvió para contextualizar esta experiencia tan dura, entendiendo cómo esta pérdida actual volvía a conectar con las pérdidas anteriores, además de ir encontrando nuevas formas de manejar sus deseos y miedos en las relaciones. En el transcurso de la terapia Sara inició otra relación sentimental y en esta ocasión ella se sintió respetada y bien tratada, con la confianza y la seguridad suficientes que le permitieron vivir las relaciones sexuales de una forma positiva. Esta relación se rompió cuando él cambió de trabajo y se trasladó a otra ciudad. Además, él reconoció que no se sentía en este momento preparado para implicarse en una relación, puesto que aún no se había recuperado del abandono por parte de su anterior pareja. Sara volvió a sentirse deprimida, decepcionada y enfadada ante otro "fracaso". Sin embargo también pudo reconocer que él era, a pesar de todo, un hombre noble y honesto, y que esta experiencia había sido para ella mucho más positiva que la anterior. Además, hablamos en terapia del logro que significaba para ella dar nuevos pasos, asumir el riesgo de mostrarse más abierta, y tener mayor experiencia en la relación con los hombres para dejar de verse frente a ellos "torpe, como una niña pequeña", y empezar a vincularse como una mujer adulta, que desea el contacto y la intimidad con un hombre, y que decide lo que quiere.

\section{Las narrativas de género y culturales}

La perspectiva sistémica nos lleva a conectar las dificultades actuales de Sara con los contextos relacionales que las originaron o las mantienen, tal como hemos expuesto hasta ahora. Exploramos también los valores, creencias y mundo de significados en su familia y su entorno social de origen en cuanto al género y la inmigración, que son dos temas muy determinantes en la vida de Sara. Esto sirve para hacer más visibles los guiones o narrativas a través de los que Sara da sentido a su vida, reconocer cómo siguen actuando en su vida en el presente, y cuestionar, ampliar o modificar aquellos que no encajan o limitan su propia experiencia.

El rol de la mujer. Narrativas de género: En la familia de origen, especialmente la materna, existe la creencia de que el destino de toda mujer es tener pareja e hijos. Sara tiene un cierto lugar de prestigio en la familia, al ser una pionera en conseguir una brillante carrera profesional y una buena posición económica. Pero también es implícitamente cuestionada o descalificada por su madre, su madrastra y otras mujeres de la familia por seguir soltera y sin hijos. Le preguntan sobre el tema cada vez que visita a su familia, especialmente en una ocasión reciente en que viajó a su país para asistir a la boda de su hermana paterna; le dicen que no sea tan exigente, y que, "con la edad que tiene, si no consigue pareja, al menos debería plantearse tener un hijo, que la cuide cuando sea mayor".

En realidad, todas las mujeres de su familia materna a lo largo de tres generaciones (su abuela y las hermanas de ésta, su madre y sus tías, y sus primas) han sido madres solteras, ya que los hombres no han permanecido implicados ni en la relación de pareja ni apenas como padres (excepto su propio padre). Sara teme que haya una especie de "maldición" en la familia materna que impida a las mujeres tener un hombre a su lado. En 
cuanto a su familia paterna, la creencia de la madrastra es que una vez casada una mujer renuncia a posibles proyectos vitales o profesionales independientes y a partir de entonces su vida debe girar en torno a su marido y a sus hijos. Eso es lo que Purificación hizo con su marido, el padre de Sara, y lo que la hija menor, Mónica, ha comenzado a hacer en su reciente matrimonio. Sara se debate internamente entre ese guión que considera que el matrimonio y la maternidad son lo único que da sentido a la vida de una mujer, y otros posibles guiones que se han abierto para ella desde que vive en España, en los que la vida en pareja o la maternidad son deseables pero no "obligatorias", y cada mujer puede decidir a qué quiere dar prioridad en su vida o qué modelo de pareja o familia desea establecer.

La immigración: Sara también ha vivido inmersa en la creencia familiar y cultural de que la lealtad a la familia está por encima de todo, de forma que si alguien emigra y consigue un trabajo, debe siempre ahorrar dinero para las necesidades de quien se queda en el país de origen. Uno no debe permitirse ser totalmente independiente, ni tampoco instalarse del todo en el país de acogida. Se debe vivir aquí de forma transitoria, con la mirada puesta en el país de origen y "con las maletas preparadas" por si hubiese que regresar en cualquier momento. Así, Sara habla de cómo muchos de sus compatriotas viven en habitaciones de alquiler en pisos compartidos y nunca se alquilan un piso o se compran muebles, puesto que eso implicaría que están instalándose más en España. Por eso, ella entra en conflicto cuando decide alquilar un piso para ella sola, amueblarlo a su gusto, o centrarse más en su vida en Madrid. ¿Tiene realmente derecho a ser independiente, a vivir su vida? ¿Puede gastarse el dinero en lo que le dé la gana, o debe anteponer siempre las necesidades más urgentes de su familia? Sara habla de cómo a veces oye la "voz de la conciencia" que le dice que está de paso aquí, y que es egoísta si emplea el dinero en sí misma.

¿Qué vida quiere construir Sara como mujer y como inmigrante? ¿Se siente identificada con estos valores y expectativas de su familia y su entorno de procedencia? El malestar que a veces siente, ¿realmente se aliviaría si su vida encajase más en estos esquemas? Revisamos su historia y las elecciones que ella ha ido haciendo: completar una carrera universitaria, conseguir una beca para estudiar un Master, venir sola a España e iniciar aquí una nueva vida, conseguir trabajo y adaptarse a un entorno profesional muy competitivo, hacer frente probablemente a prejuicios por ser inmigrante, ser económicamente independiente, etc. Estos desafíos descomunales a los que Sara ha hecho frente ponen de relieve sus capacidades, su fuerza y determinación. Además, indican que desde hace mucho tiempo ella ha ido haciendo elecciones para construirse una vida muy diferente del resto de mujeres de su familia y de otros inmigrantes procedentes de su mismo entorno. Sara puede ahora ir reconociendo cómo esta narrativa familiar y de género ha ido moldeando su vida, comprender y respetar las elecciones que han hecho otras mujeres en su familia, y también puede ir encontrando dentro de sí las respuestas de qué es lo que la hace sentir bien, qué modelo de mujer quiere ser, cómo quiere construir sus relaciones, su trabajo, su vida. Va sintiéndose progresivamente más autora de su propio guión, en lugar de dedicarse a ejercer, sin cuestionarlo, el papel que tenía asignado, o de sentirse víctima de esos "mandatos" externos.

Recientemente Sara hizo frente a varios momentos críticos en los que pudo dar pasos para cambiar estas narrativas. Se mudó a un apartamento ella sola, al regresar su compañera de piso a su país, y esto puso más de relieve su elección de apostar por su vida en Madrid en lugar de vivir aquí con la sensación de estar de paso. Cumplió así un deseo, a la vez que afrontaba más de lleno tanto su soledad como su proyecto de vida independiente de su familia. Este cambio coincidió en el transcurso de dos meses con su ruptura de la relación sentimental, con su viaje a su país para asistir a la boda de su hermana y con un mayor nivel de presión y exigencia de su trabajo. Sara sufrió un incremento de los síntomas depresivos y ansiosos en esta época. Además se acercaban las navidades y ella temía ese momento; si se quedaba en España se iba a sentir muy sola; si volvía a su país se iba a repetir la historia (como en la boda de la hermana) de sentirse observada, criticada por no tener "aunque fuera un hijo" y con peticiones de dinero de parte de las mujeres de la familia. Pero precisamente también ésta fue una ocasión para hacer un "experimento" y llevar a la práctica los cambios que ella estaba comenzando aquí. Se trataba de ver si podía ir a su país y familia de origen mostrando 
esa faceta suya de mujer más "europea”, más independiente, con menos culpa por hacer lo que le gusta y cuidarse. Esta vez no iba a volver a su casa como una especie de Papá Noel con regalos para todos, ya que se iba a gastar el dinero en otro billete de avión y no podía ni quería asumir más gastos. Así que disfrutaría de la compañía de su familia, empezando también a cuidarse y a mostrar más explícitamente sus necesidades, a la vez que pondría límites a las peticiones de dinero extra o de cualquier otro reclamo del habitual rol de "proveedora". Anticipamos cómo ella podría hacer frente a posibles situaciones de reproche o crítica, que se dieron sólo en el caso de su hermana materna, acostumbrada al rol de Sara como la hermana mayor que todo lo soluciona. Este viaje fue una experiencia muy positiva para Sara, que pudo entrenarse en una nueva forma de estar con su familia, cambiando su lugar en la relación sin ceder a las expectativas externas, sin sentirse culpable y sin retraerse o cortar el vínculo, tal como habría ocurrido anteriormente. Además, a la vuelta del viaje empezó a buscar más activamente otro trabajo que le permitiese vivir menos estresada con más tiempo para su vida personal.

\section{Conclusiones}

El desarrollo de este caso ha ejemplificado el uso de conceptos y estrategias terapéuticas del enfoque sistémico que pueden aplicarse a cualquier terapia, ya sea individual, de pareja o de familia. El trabajo con el genograma nos permite contextualizar el problema por el que los pacientes acuden a consulta y darle un significado que conecte con la historia familiar y las pautas de relación más significativas. Una vez que se identifican estas pautas repetitivas, se comprueba cómo siguen actuando en el momento presente en distintos contextos relacionales, tal como hemos descrito en el caso de Sara. Así, estamos en condiciones de ayudar a los pacientes a iniciar cambios para sustituir esas pautas disfuncionales por otras que permitan nuevas experiencias y formas de relación y que conduzcan a una mayor satisfacción vital. Nos centramos en los pequeños logros conseguidos (algo que la persona sintió, pensó o hizo diferente y que apunta en dirección al cambio), y animamos a los pacientes a continuar esa práctica de nuevas modalidades de relación consigo mismos y con los demás, asignando tareas concretas o "pequeños experimentos" para realizar entre una sesión y otra. Anticipamos las posibles dificultades o resistencias internas o externas que puedan surgir ante los intentos de cambio, y abordamos también cuáles son los sistemas de creencias familiares, culturales o de género que pueden haber alimentado el mantenimiento del problema. A la vez que reconocemos y respetamos la lealtad de la persona hacia esas narrativas, las vamos cuestionando amablemente, añadiendo nuevos aspectos que las modifiquen o amplíen lo suficiente como para que favorezcan los nuevos planteamientos vitales del paciente.

La terapia con Sara continúa, aprovechando la redacción de este artículo como un momento para hacer balance de este proceso terapéutico y de los cambios conseguidos. En sus propias palabras: "Al principio vine a terapia con la única idea de dejar de sentirme mal. Luego me he ido dando cuenta de que el dolor que sentía no era sólo por las circunstancias actuales, sino por muchas otras razones. Ahora empiezo a sentir de nuevo que recupero el control, pero no es a costa de eliminar los sentimientos, como antes. La terapia me está ayudando a ver que hay más opciones para mi vida de las que yo pensaba, puesto que vivía bajo el lema de "hacer lo que hay que hacer". He ido concretando ideas que antes eran para mí mucho más difusas y vagas, por ejemplo, que puedo tener en cuenta mis necesidades en lugar de atender siempre las de mi familia; que tengo derecho a poner límites y no tengo que hacer siempre lo que se espera de mí. Puedo empezar a verme como una persona independiente, y no solamente como parte de mi familia. Miro a las mujeres de mi familia y me doy cuenta de todas sus carencias, de que viven dentro de un mundo limitado y no conocen ni se han planteado otras opciones. En cambio, yo he intentado no dejarme llevar por las circunstancias. Me siento mal por no tener pareja, pero también me doy cuenta de que he elegido no casarme con cualquiera y no tener hijos yo sola. Veo que no encajo en el guión familiar y eso me resulta a veces duro, pero en cierto modo también estoy satisfecha de ello, ya que yo quiero elegir mi propia vida." 


\section{Agradecimientos}

Quiero expresar mi agradecimiento a las dos mujeres que han colaborado conmigo para hacer realidad este trabajo: mi paciente, por su confianza y generosidad al aceptar la redacción de este artículo; y Solana Orlando, la terapeuta con quien formo un equipo de trabajo, por sus valiosas aportaciones para el desarrollo de este caso.

\section{Referencias}

Andersen, T. (1994). El equipo reflexivo. Diálogos y diálogos sobre los diálogos. Barcelona: Gedisa.

Anderson, C. y Stewart, S. (1983). Mastering resistance. A practical guide to family therapy. Nueva York: The Guilford Press.

Bentovim, A. (2000). Sistemas organizados por traumas. El abuso físico y sexual en las familias. Buenos Aires. Paidós.

Beyebach, M. (2006). 24 ideas para una psicoterapia breve. Barcelona: Herder.

Carter, B. y McGoldrick, M. (2005). The expanded family life cycle. Individual, family and social perspectives. Nueva York: Allyn and Bacon.

Friedman, S. (1995). The reflecting team in action. Collaborative practice in family therapy. Nueva York: The Guilford Press.

Haley, J. (2009). Terapia para resolver problemas. Madrid: Amorrortu.

Lerner, H. G. (1990). La afirmación personal. Barcelona: Urano.

McGoldrick, M., Anderson, C. y Walsh, F. (1991). Women in families. A framework for family therapy. Nueva York: W.W. Norton and Co.

McGoldrick, M. y Gerson, A. (2006). Genogramas en la evaluación familiar. Barcelona: Gedisa.

Papp, P. (1994). El proceso del cambio. Barcelona: Paidós.

Sluzki, C. (1992). Transformations. A blueprint for narrative changes in therapy. Family Process. No 31, págs. 217-231.

Walters, M., Papp, P., Carter, B, y Silverstein, O. (1996). La red invisible. Pautas vinculadas al género en las relaciones familiares. Barcelona: Paidós.

Watzlawick, P., Weakland, J. y Fisch, R. (1976). Cambio. Formación y solución de los problemas humanos. Barcelona: Herder.

Watzlawick, P. (1989). El lenguaje del cambio. Barcelona: Herder.

White, M. (1997). Guías para una terapia familiar sistémica. Barcelona: Gedisa.

White, M. y Epston, D. (1993). Medios narrativos para fines terapéuticos. Barcelona: Paidós.

Manuscrito recibido: 07/01/2010

Revisión recibida: 31/01/2010

Manuscrito aceptado: 02/02/2011 